УДК 343.3

\title{
СУБЪЕКТ СОЗДАНИЯ С ЦЕЛЬЮ ИСПОЛЬЗОВАНИЯ, РАСПРОСТРАНЕНИЯ ИЛИ СБЫТА, А ТАКЖЕ РАСПРОСТРАНЕНИЕ ИЛИ СБЫТ ВРЕДОНОСНЫХ ПРОГРАММ ИЛИ ТЕХНИЧЕСКИХ СРЕДСТВ
}

\author{
(C) 2013 г. $\quad$ О. А. Кирбятьев
}

\section{Днепропетровский государственный университет внутренних дел}

Статья посвящена изучению субъекта состава преступления, предусмотренного ст. 361-1 УК Украиньл. В статье проводится анализ с иелью определения возраста субъекта, с которого может наступать уголовная ответственность.

Ключевые слова: субъект преступления; уголовная ответственность; возраст уголовной ответственности.

In the article author presents the studies on the subject of corpus, foreseen by art. 361-1 of Ukraine Penal Code. In the article is also presented the analysis of determining the subjects'age, which criminal responsibility can come from.

Key words: subject of crime; criminal responsibility; age of criminal responsibility.

Под субъектом преступления понимается минимальная совокупность признаков, которые характеризуют лицо, совершившее преступление, необходимые для привлечения его к уголовной ответственности, а именно: физическое лицо, возраст и вменяемость. В действующем Уголовном кодексе закреплен раздел, который содержит понятие и признаки субъекта преступления. В ч. 1 ст. 18 УК Украины отмечено, что субъектом преступления является физическое вменяемое лицо, которое совершило преступление в возрасте, с которого, согласно закона, может наступать уголовная ответственность.

Относительно возраста, установленного по отношению к субъекту исследуемых правонарушений, законодатель имеет однозначную позицию. Субъектом противоправных деяний, предусмотренных ст. 361-1 УК Украины, является физическое лицо с 16-ти лет. Но современные исследования свидетельствуют о том, что данный взгляд является несколько устаревшим. Так, в научной литературе нет единства относительно определения возраста лиц, которые совершают преступления исследуемой категории. Некоторые авторы указывают возраст правонарушителей, кото- рые совершают преступления с применением средств компьютерной техники в пределах 15-45 лет [2; 13], некоторые расширяют пределы до 14-45 лет [3], а определенные исследования устанавливают нижний возрастной предел совершения таких правонарушений на уровне одиннадцати лет [9].

Но такие тенденции выделяются относительно всего комплекса деяний, которые связаны с использованием программных и технических средств. Относительно создания с целью использования, распространения или сбыта, а также распространения или сбыта вредоносных программных или технических средств отдельных данных, в научной литературе не приводится.

Законодатель, исходя из сложности объективной стороны, характера и степени опасности преступления, не счел возможным изменить возраст субъекта компьютерного преступления. Однако такое решение не всегда оценивается однозначно. Достаточно распространенной является мысль о том, что часто компьютерные преступления совершаются лицами, которые не достигли шестнадцати лет, потому установление общего возраста уголовной ответственности за эти преступле- 
ния может привести к неэффективности механизма уголовно-правовой защиты информационных отношений.

Достаточно обоснованно, что основанием для снижения законодателем возраста уголовной ответственности за определенные преступления является совокупность таких критериев:

1) определенный уровень умственного развития, сознания лица, который свидетельствует о возможности в определенный возраст осознавать общественную опасность и противоправность преступлений;

2) значительная распространенность среди подростков;

3) значительная общественная опасность (тяжесть) преступлений [7].

Из этих критериев можно исходить, решая вопрос о целесообразности или нецелесообразности снижения возраста субъекта создания с целью использования, распространения или сбыта, а также распространения или сбыта вредоносных программных или технических средств.

Как отмечает Т. В. Михайлина, хотя компьютерные преступления, совершенные лицами, которые не достигли шестнадцати лет, действительно могут причинить тяжелые последствия, личность несовершеннолетнего характеризуется определенной спецификой: в первую очередь ей присущая заинтересованность самим процессом работы с компьютерной техникой, желание определить свои способности в управлении сложной компьютерной техникой. Осознание возможности причинения вреда владельцу информации, а следовательно осознание общественной опасности, противоправности вмешательства в работу электронно-вычислительных машин, систем и компьютерных сетей, не воспринимается в большинстве случаев как реально возможный и желаемый результат [10]. Так, 15-летний гражданин Хорватии Вице Мешкович, желая показать свое умение, осуществлял неоднократный несанкционированный доступ к компьютерной информации, которая принадлежала ВВС США [6]. В одном из официальных сообщений Министерства юстиции США шла речь о задержании несовершеннолетнего, который с той же целью использовал компьютер для выведения из строя контрольной башни аэропорта в Бо- стоне [15]. То есть несовершеннолетний может не иметь прямого умысла на совершение общественно опасного деяния и реально не осознавать последствий своих действий.

Что касается такого критерия, как распространенность компьютерных преступлений среди несовершеннолетних, которые не достигли шестнадцатилетнего возраста, то статистические данные не подтверждают этот вывод. Исследования зарубежных криминологов показали, что возраст 36\% лиц на момент совершения компьютерного преступления не превышал 20 лет, 51\% имели возраст от 20 до 40 лет, а 13\% - больше 40 лет [1]. А. Кузнецов приводит данные о том, что половина хакеров, арестованных, в США, имеют возраст от 25 до 30 лет и только седьмая часть - до 21 года [8]. По мнению руссийских исследователей, большинство хакеров - лица в возрасте от 16-17 до 20-25 лет. В этом возрасте способность к восприятию информации наиболее высока, что особенно важно для компьютерных преступлений [12]. Следовательно, обоснованным будет вывод о том, что совершение создания с целью использования, распространения или сбыта, а также распространение или сбыт вредоносных программных или технических средств лицами, которые не достигли шестнадцати лет, не является распространенным.

Все это свидетельствует об отсутствии тех критериев, которые могли бы обусловить повышенную степень общественной опасности создания с целью использования, распространения или сбыта, а также распространение или сбыт вредоносных программных или технических средств, совершенного лицом, которое не достигло шестнадцати лет, и о возможности ее исправления другими, не уголовно-правовыми, мероприятиями, a, следовательно, позволяет сделать вывод о, как минимум, нецелесообразности снижения возрастного предела субъекта компьютерных преступлений.

Таким образом, установление в ст. 22 УК Украины общего возраста уголовной ответственности за компьютерные преступления кажется социально обоснованным.

Правоохранительными органами зарубежных стран зарегистрировано значительное число случаев, когда малолетние преступники осуществляли торговлю похищен- 
ными номерами кредитных карт, получая преступные доходы, измеряемые тысячами долларов. Но это данные зарубежных стран. Практика же в Украине показывает несколько иную статистику. Ее мы рассмотрим ниже.

Анализ следственной практики показал увеличение количества дел, в возбуждении которых было отказано, в связи с недостижением лица возраста уголовной ответственности. Однако к ним были применены меры воспитательного характера, что явилось не мене эффективным воздействием на, еще не полностью сформировавшееся, сознание и мировосприятие несовершеннолетних, и показало высокую превентивность данных мер.

С целью определения возраста, с которого должна наступать ответственность за создание, с целью использования, распространения или сбыта, а также распространения или сбыта вредоносных программных или технических средств, рассмотрим результаты опроса, проведенного автором относительно количества противоправных посягательств, которые криминализированы ст. 361-1 УК Украины, которые совершаются лицами разных возрастных групп, а также проанализируем статистику приговоров украинских судов, вынесенных в 2009-2012 годах по ст. 361-1 УК Украины относительно лиц, которые совершили данное преступление.

Исследование в этом направлении проводилось по четырем возрастным группам: 14-15 лет (школьники; группа лиц, которые не являются субъектами уголовной ответственности по ст. 361-1 УК Украины) - 21\%; 16-17 лет (несовершеннолетние - субъекты преступления по ст. 361-1 УК Украины) $23 \% ; 18-25$ лет (в абсолютном большинстве являются студентами ВУЗов и средних специальных заведений, в том числе значительная часть студентов, которые учатся на инженерно-технических специальностях) - 27\%; 25 и больше лет (преимущественно лица с более высоким, преимущественно техническим образованием, которые работают на должностях, непосредственно связанных с эксплуатацией или обслуживанием компьютерной техники) - 29\%. Было опрошено 227 лиц. Опрашивались широкие слои населения, но значительное внимание уделялось лицам, которые пробовали устанавливать на свой компьютер и(или) занимались рассыл- кой и(или) сами писали (создавали) компьютерные вирусы (взламывали защиту других компьютеров). Если рассматривать показатели без учета возрастных ограничений, то на вопрос «Пробовали ли Вы рассылать или устанавливать на ПК вирусы?», ответы: да; устанавливал лишь на свой ПК; не только занимался рассылкой, но и сам пишу - выбрали 36 опрошенных (15,9\% от общего количества), что само по себе является достаточно высоким показателем. С другой стороны, такой результат можно считать даже несколько заниженным, если учесть вероятное нежелание некоторых лиц сознаться в совершенном, хотя опрос проводился анонимно. Основной же целью такой выборки был учет скрытой деятельности, цели и мотивов группы лиц, которая наиболее склонна к совершению преступлений исследуемого вида. Следовательно, опрос показал, что при наличии достаточно высокого уровня знаний и навыков (что объясняется традиционно сильной школой точных наук на постсоветском пространстве), представители технических специальностей чаще всего имеют достаточно низкий уровень правосознания и правовой культуры, уделяя большее внимание исследовательскому интересу.

Среди лиц, которые сознались в определенных действиях с вредоносными программными средствами, к возрастной категории 14-15 лет относятся 5 лиц (что составляет $13,9 \%$ от общего количества лиц, которые избрали любой вариант ответа), к категории 16-17 лет - 6 лиц (16,7\%), к категории 18-25 лет и старше - 25 лиц $(69,4 \%)$. Из всех указанных лиц студенты технических специальностей составляют 27\%. Это относительно невысокий процент. Поэтому утверждать, что студенты именно технических специальностей более склонны к совершению преступления по ст. 361-1 УК Украины, мы не можем. Кроме этого, результаты проведенного социологического исследования четко показали то, что количество несовершеннолетних (возрастом 14-17 лет), которые занимались противоправними действиями, связанными с установкой, рассылкой компьютерных вирусов или взломом других компьютеров (30,6\%), почти вдвое меньше количества совершеннолетних (18 лет и выше) - 69,4\%. Высокий процент количества совершеннолетних лиц, 
по нашему мнению, вероятно включает их противоправные действия с компьютерными вирусами, начиная с их несовершеннолетия. То есть кое-кто из совершеннолетних стал заниматься противоправними действиями с компьютерными вирусами с несовершеннолетия, а кое-кто впервые сделал это, находясь уже в совершеннолетнем возрасте. Но, ввиду результатов исследования, уверенно можно констатировать, что удельный вес несовершеннолетних лиц младше 18-ти лет остается сравнительно невысоким, и не превышает аналогичный у совершеннолетних.

Кроме этого, интересным и одним из ключевых показателей в результате проведенного социологического исследования, мы считаем показатель мотивации совершения незаконных действий респондентами по установлению, рассылке компьютерных вирусов или взлому других компьютеров. Сам вопрос, почему они решили это сделать, поможет нам верно определить возраст, с которого обоснованно можно установить ответственность за совершение исследуемого преступления, и избрать оптимальный вид наказания, будь-то ограничение свободы, общественные работы или применение мер воспитательного характера.

Следовательно, при ответе на вопрос «Если Вы занимались установлением, рассылкой компьютерных вирусов или взломом других компьютеров, скажите, зачем Вы это делали?», 24\% ответили, что им было интересно сделать это, $32 \%$ ответили, что они сделали это потому, что хотели узнать смогут ли они это сделать («спортивный интерес»), 4\% сделали это из мести, 18\% просто так сделали это, и только 15\% совершили противоправные действия из корыстных побуждений, 7\% указали на другую причину своих действий. Корыстный мотив был присущ лишь 15\% опрошенных. Кроме этого, все 15\% респондентов имели совершеннолетний возраст. Другой (некорыстный) мотив среди совершеннолетних был присущ лишь нескольким лицам. А несовершеннолетние, в свою очередь, при совершении указанных противоправных действий, имели целью исключительно познавательный, исследовательский интерес. Им была интересна исключительно сама вероятность достижения результата.

Причем, если речь идет о распростране- нии вредоносных программ для электронно-вычислительных машин, то подростками совершается наибольшее количество из данной категории преступлений. В меньшей степени это касается создания таких программ, поскольку для совершения общественно опасного деяния в форме написания нового вируса, по меньшей мере, необходимы специальные знания. Это подтверждают и результаты опроса, где вариант «не только занимался рассылкой вирусов, но и сам пишу их» выбрали преимущественно респонденты третьей (18-25 годы) и четвертой (25 лет и старше) возрастной группы. Установлением же на свой компьютер вредоносных программ или обменом ими с друзьями занимались преимущественно несовершеннолетние лица, много из которых и не представляли, что они подпадают под действие ст. 361-1 УК Украины.

Отсюда можно констатировать, что несовершеннолетние преимущественно экспериментируют с вредоносными программами. Такая цель, как причинение конкретного вреда у них отсутствует в отличие от лиц - студентов и старше их, которые, во-первых, имея соответствующие знания, уже могут сами создавать вирусы, а, во-вторых, создавая их или используя, имеют конкретную цель, преимущественно корыстную. Считаем, что такие действия таких лиц должны быть однозначно криминализированы и, соответственно, наказаны.

T. В. Михайлина отмечает, что совершения создания с целью использования, распространения или сбыта, а также распространения или сбыта вредоносных программных или технических средств, которые совершаются несовершеннолетними, составляют значительную угрозу, особенно в случаях, когда они остаются незамеченными. Избежание наказания повышает уверенность подростка в своих силах, дает толчок для продолжения преступной деятельности, что в будущем может привести к переходу несовершеннолетнего лица в более опасную категорию компьютерных правонарушителей и даже присоединения к организованным преступным группировкам [10]. С ней трудно не согласиться, но, на наш взгляд, учитывая результаты социологического исследования, проведенного автором относительно моти- 
вов совершения действий с вредоносными программами несовершеннолетними, и принимая во внимание результаты изучения уголовных дел по ст. 361-1 УК Украины, по которым были вынесены приговоры, считаем, что применение к несовершеннолетним мер воспитательного в полной мере выполнит свою превентивную функцию.

Кроме того, сторонниками нецелесообразности снижения возраста уголовной ответственности за компьютерные преступления, выступают С. О. Орлов [11] (который на основании анализа приведенных в научной литературе критериев (криминологических - распространенность определенного вида деяния среди лиц определенного возраста, их тяжесть и т. п.; биологических - уровень психического и физического развития, интеллектуальных, волевых свойств лица; социологических - уровень социализации лица) и Н. В. Карчевский [5] (который ссылается на сложность объективной стороны таких деяний), которые отмечают нецелесообразность снижения данного вида.

Если же проанализировать статистику приговоров судов Украины 2005-2010 гг. относительно возраста лиц, которые были привлечены к уголовной ответственности по ст. 361-1, предоставленную Государственной судебной администрацией Украины, можно четко увидеть, что все привлеченные к уголовной ответственности по указанной стате лица, имели возраст на момент совершения преступления 18 лет и выше. Одно лицо имело возраст 58 лет [4].

Поэтому считаем, что нет необходимости криминализировать действия несовершеннолетних. Предлагаем на основании выше изложенных фактов, результатов опроса и данных статистики, повысить возраст наступления уголовной ответственности по ст. 361-1 УК Украины до 18-ти лет. Это, по нашему мнению, будет способствовать гуманизации наказания за исследуемое преступление, которое вместе с тем обеспечит надлежащую правовую охрану нормы и наряду с другими мероприятиями, будет играть роль общей и специальной превенции, а также не противоречить концепции охраны и защиты прав человека.
Литература

1. Біленчук П. Д., Романюк Б. В., Цимбалюк В. C. та ін. Комп'ютерна злочинність: Навчальний посібник. - К.: Атіка, 2002. $131 \mathrm{c}$.

2. Вехов В. Б. Компьютерные преступления: Способы совершения, методики расследования. / Под ред. Б. П. Смагоринского. М.: Право и закон, 1996. - 182 с.

3. Голубев B. Компьютерная преступность - проблемы и решения [Электронный pecypc] / Информационный сервер центра исследований компьютерной преступности. - Режим доступа: http://www.crime-research. ru/articles/golubev_sept/4, свободный. - Загл. с экрана.

4. Державна судова адміністрація України. Реєстр судових рішень. [Электронный ресурс] / Інформаційний сервер Державної судової адміністрації України. - Режим доступа: http://www.court.gov.ua, свободный. Загл. с экрана.

5. Карчевський М. В. Кримінальна відповідальність за незаконне втручання в роботу електронно-обчислювальних машин (комп'ютерів), систем та комп'ютерних мереж (аналіз складу злочину): автореф дисс. ... канд. юрид. наук: 12.00.08. / Карчевський Микола Віталійович; Національна юридична академія України ім. Ярослава Мудрого. X., 2003. - 19 c.

6. Компьютерные террористы: новейшие технологии на службе преступного мира. / Авт.-сост. Т. И. Ревяко. - Минск: Литератуpa, 1997. - 219 c.

7. Кримінальне право України: Загальна частина: Підручник для студентів юрид. спец. вищ. закладів освіти. / М. І. Бажанов, Ю. В. Баулін, В. І. Борисов та ін.; за ред. професорів М. І. Бажанова, В. В. Сташиса, В. Я. Тація. - Київ-Харків: Юрінком Інтер-Право, 2001. - $184 \mathrm{c}$.

8. Кузнецов А. Пираты в Интернете. // Милиция. - 2000. — №2. - С. 27.

9. Менжега М. М. Особенности установления личности хакера. // Закон и право. 2004. - №8.

10. Михайліна T. В. Кримінальна відповідальність за створення з метою використання, розповсюдження або збуту шкідливих програмних чи технічних засобів, а також 
їх розповсюдження або збут: дисс. ... канд. юрид. наук: 12.00.08. / Михайліна Тетяна Вікторівна; Київський національний університет внутрішніх справ. - К., 2010. - 236 с.

11. Орлов C. О. Кримінально-правова охорона інформації в комп'ютерних системах та телекомунікаційних мережах: автореф дисс. ... канд. юрид. наук: 12.00.08. / Орлов Сергій Олександрович; Національний ун-т внутрішніх справ. - Х., 2004. - 20 с.

12. Расследование неправомерного доступа к компьютерной информации. / Под. ред. Н. Г. Шуруханова. - М.: Щит-М, 1999. - 123 c.

13. Сударева Л. А. Личность преступни- ка, совершающего компьютерные преступления. // Вестник Московского университета МВД России. - 2007. - №1. - 132 с.

14. Уголовное право Украины. Общая и особенная части: учебник. / Под ред. Е. Л. Стрельцова. - Х.: ООО «Одиссей», 2006. - $720 \mathrm{c}$.

15. Juvenile Computer Hacker Cuts off FAA Tower at Regional Airport - First Federal Charges Brought Against a Juvenile for Computer Crime (March 18, 1998) [Электронный ресурс] // US Department of Justice. - Peжим доступа: http://www.usdoj.gov/criminal/ cybercrime/juvenilepld.html, свободный. Загл. с экрана.

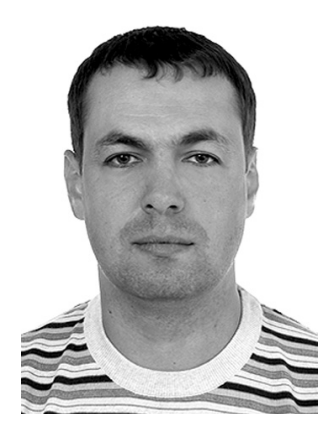

Олег Александрович Кирбятьев - майор милиции, адъюнкт кафедры уголовного права и криминологии Днепропетровского государственного университета внутренних дел.

Oleg Aleksandrovich Kirbatyev - police major, adjunct at the Penal Law and Criminology department of the Dnepropetrovsk State University of Internal Affairs.

69124, Украина, г. Запорожье, ул. Курузова, 11А, кв. 82

11A Kuruzova st., app. 82, 69124, Zaporozhye, Ukraine

Тел.: +38 (063) 463-41-72; e-mail: cobrian@mail.ru 